DOI 10.37882/2223-2982.2021.12.07

\title{
ПСИХОЛИНГВИСТИЧЕСКИЙ АСПЕКТ МОДЕЛИРОВАНИЯ ВО ФРАЗЕОЛОГИИ
}

\section{PSYCHOLINGUISTIC ASPECT OF MODELING IN PHRASEOLOGY}

A. Ergazina

Summary: There are 3 main approaches to the study of phraseology: cognitive, traditional and psycholinguistic. Each approach opens up opportunities for identifying and exploring a specific aspect of phraseology. Within the framework of this study, we will consider the psycholinguistic aspect. The performed analysis of the available research revealed that within the framework of psycholinguistics, scientists are making efforts to solve a number of phraseology problems, these problems are considered in the work. The analyzed studies are of great importance for the study of the psycholinguistic aspect in the modeling of phraseology. It was demonstrated that the psycholinguistic aspect is best manifested in the study of the identification of phraseological units, as well as the functioning of phraseological units in the lexicon. However, the analyzed studies did not consider syntactic mobility, the degree of fame, the possibility of occasional transformations, which forms the basis for further research. It was revealed that the process of modeling phraseology is determined by such semantic features as the degree of idiomatization, the degree of complication, associations of conventional meaning and form. The process of modeling and identification of the meaning of phraseological units can be influenced by the context and individual characteristics of a person (gender, profession, territory, etc.).

Keywords: phraseological units, psycholinguistics, lexicon, phraseology, modeling.

\author{
Ергазина Алия Абдирамановна \\ К.п.н., доцент, Баишев Университет \\ (2. Актобе, Республика Казахстан) \\ yergazina1@mail.ru
}

Аннотация: Выделяют 3 основных подхода к изучению фразеологии: когнитивный, традиционный и психолингвистический. Каждый подход открывает возможности для определения и исследования определенного аспекта фразеологии. В рамках данного исследования рассмотрен психолингвистический аспект. Выполненный анализ имеющихся исследований выявил, что в рамках психолингвистики ученые прилагают усилия для решения ряда проблем фразеологии, данные проблемы рассмотрены в работе. Проанализированные исследования имеют большое значение для изучения психолингвистического аспекта в моделировании фразеологии. Было продемонстрировано, что психолингвистический аспект лучше всего проявляется в изучении идентификации фразеологических единиц, а также функционировании фразеологизмов в лексиконе. Однако в проанализированных исследованиях не рассматривались синтаксическая подвижность, степень известности, возможность окказиональных трансформаций, что формирует задел на дальнейшие исследования. Было выявлено, что процесс моделирования фразеологии определяется такими семантическими особенностями как степень идиоматизации, степень осложненности, ассоциации конвенциального значения и формы. На процесс моделирования и идентификации значения фразеологизмов могут влиять контекст и индивидуальные характеристики человека (пол, профессия, территория и т.д.).

Ключевые слова: фразеологизмы, психолингвистика, лексикон, фразеология, моделирование.

1. Нахождение фразеологизмов в лексическом «хранилище» или их функционирование в качестве лексических единиц;

2. Разбивка фразеологизмов на отдельные части в процессе осознания и понимания;

3. Выбор способа идентификации фразеологизмов: переносного или буквального;

4. Базовые когнитивные процессы, которые обеспечивают понимание фразеологизмов;

5. Опоры и стратегии, которые используются для идентификации и понимания фразеологизмов [4, $5,6,7,8]$.

Исследователь Гиббс Р. в результате изучения вопроса о разделении фразеологизмов на отдельные компоненты и особенности их изучения, переработки, пришел к выводу, что люди обрабатывают устойчивые выражения композиционно, то есть сначала из ментального лексикона извлекается значение отдельных составляющих устойчивого выражения, а затем они сочетаются на базе 
синтаксических языковых правил. Важно отметить, что в данной ситуации понимание идиоматизированной лексики реализуется в течение минимального времени [5]. Но в исследовании Гиббса Р. не рассматривается вопрос буквальной интерпретации устойчивых выражений, которая не зависит от контекста.

Одна из причин, выявленная Гиббсом Р. заключается в метафорическом картировании информации на подсознательном уровне при пересечении концептуальных областей. Детализированный анализ ментальных фразеологических образов обнаружил, что люди обладают подсознательным знанием метафорической базы фразеологизмов [9]. Проведенные Гиббсом Р. исследования также доказали, что когнитивная типология исходной области является наиболее выраженной и яркой в долговременной памяти в ходе метафорического картирования при пересечении когнитивных областей. Это имеет решающее значение для понимания устоявшихся выражений.

Отдельные концептуальные метафоры соответствуют не всем фразеологизмам, проведенные психолингвистические исследования демонстрируют, что люди понимают фразеологизмы метафорически за счет базовых знаний. На основании исследований Гиббса Р. была сформулирована гипотеза прямой интерпретации, согласно которой определение значения фразеологизма предшествует моделированию его буквального значения и реализуется, когда переносное значение идет в разрез с текущим контекстом.

Модели фразеологии, которые позволяют идентифицировать устойчивые выражения, рассматривались ранее в исследованиях В. Швейгерт и Дж. Данбар [10, 11]. Было выявлено, что процесс переработки фразеологизмов напрямую связан с тем фактом, насколько о них у индивида сформированы предварительные знания.

Исследования Дж. Данбара также продемонстрировали, что при переработке фразеологизмов имеет место и холистический или целостный способ, который характерен для детского возраста, однако может использоваться и во взрослом возрасте. Исследователь считает, что переработка фразеологизмов может осуществляться индивидами различными способами.

Исследования Дж. Данбара также демонстрируют, что на основании полученных нейрофизиологических данных можно сформулировать предположение о том, что моделирование фразеологии может обуславливаться особенностями обработки информации полушариями мозга. При этом левое полушарие связано с буквальной переработкой, а правое - с переработкой знакомых фраз.

Правое полушарие, вероятно, связано с переработ- кой знакомых фраз, а левое - с буквальной переработкой. Правое полушарие при этом упоминается и в контексте глубокой дислексии [11].

Также внимания заслуживают идеи Э. Катлера и Д. Суинни, которые предложили концепции переработки фразеологизмов [12]. Первая концепция представляет собой гипотезу списка идиом, согласно которой идиомы входят в специальный перечень каждого человека, не являясь частью общего лексикона. Согласно данной гипотезе, когда человек встречает фразеологизм, он сначала имеет дело с ее буквальным значением. Если в текущих условиях выражение неуместно, процесс восприятия обретает идиоматическую направленность, из перечня находится переносное значение. Данная гипотеза описывает модель буквальной переработки устойчивых выражений.

Вторая концепция представляет собой гипотезу лексической репрезентации, согласно которой устойчивые выражения находятся в ментальном лексиконе каждого отдельного человека в качестве отдельных слов и, соответственно, извлекаются из лексикона подобно словам. Когда происходит интерпретация устойчивых выражений, она начинается с первого слова, а затем конструируется буквальное значение, что соответствует традиционному подходу синтаксической и семантической переработки.

Таким образом, концепции Э. Катлера и Д. Суинни демонстрируют, что моделирование фразеологизма, конструирование буквального и переносного значения реализуются параллельно, что описывает модель одновременной переработки.

Помимо зарубежных психолингвистических исследований, посвященных вопросам моделирования фразеологии, хранения, восприятия и понимания устойчивых выражений, высокий научный интерес представляют отечественные работы.

И.В. Жернакова в ходе экспериментального исследования на основании полученных эмпирических данных выделила 3 основных стратегии идентификации фразеологизмов:

- Разделение устойчивого выражения;

- Выделение в устойчивом выражении семы;

- Переосмысление семы, как правило, на базе метафорического переноса.

Проведенное исследование позволило И.В. Жернаковой сделать вывод о том, что при известном многообразии стратегий идентификаций фразеологизмов в преимущественном количестве случаев наблюдаются многоступенчатые импликации, расхождения образов и признаков контактирующих культур, взаимное использование энциклопедических и языковых знаний [7]. 
В работах О.С. Шумилиной приводятся результаты анализа моделей переработки устойчивых выражений с применением ряда процедур. В своих исследованиях О.С. Шумилина целью видит определение и составление характеристики опор и стратегий, применяемых для идентификации фразеологических единиц с соматическими компонентами, а также определение и описание особенностей идентификации лексических новообразований. Наиболее значимым является вывод, согласно которому при идентификации устойчивых выражений иностранных языков человек опирается на значения компонентов фразеологической единицы, являющихся свободно употребляемыми словами, при этом актуализируются ассоциативные связи.

О.С. Шумилина в своих исследованиях демонстрирует, что установленные стратегии идентификации неологизмов имеют универсальный характер и проявляются в ходе взаимодействия, работы устойчивыми выражениями как иностранных языков, так и родного языка. О.С. Шумилина выделила 7 стратегий идентификации фразеологических единиц: координация между языками; контекстуальная субституция; буквализация; от противного; десимволизация; замена компонентов; членение на компоненты.

При рассмотрении психолингвистического аспекта в моделировании фразеологии было выявлено, что наиболее актуальными являются следующие стратегии: прямая дефиниция, мотивирующая стратегия, категоризация.

Проведенные исследования продемонстрировали, что, когда носители русского языка идентифицируют иностранные фразеологические единицы, они преимущественно используют следующие стратегии и приемы:
1. Контекстуальные. Используется слово или словосочетание из контекста или контекст в целом.

2. Межязыковые и внутриязыковые. Напрямую взаимосвязаны со структурой, составными компонентами фразеологизма.

Было выявлено, что особенности идентификации фразеологизмов зависят от таких семантических параметров как степень переосмысления значения, специфика образа, изоляция или наличие контекста, внутренняя форма и т.д. Особое внимание необходимо уделять вариативности понимания фразеологизмов, что обусловлено ассоциативной природой значения фразеологических единиц.

Проанализированные исследования имеют большое значение для изучения психолингвистического аспекта в моделировании фразеологии. Было продемонстрировано, что психолингвистический аспект лучше всего проявляется в изучении идентификации фразеологических единиц, а также функционировании фразеологизмов в лексиконе. Однако в проанализированных исследованиях не рассматривались синтаксическая подвижность, степень известности, возможность окказиональных трансформаций, что формирует задел на дальнейшие исследования.

Таким образом, процесс моделирования фразеологии определяется такими семантическими особенностями как степень идиоматизации, степень осложненности, ассоциации конвенциального значения и формы. На процесс моделирования и идентификации значения фразеологизмов могут влиять контекст и индивидуальные характеристики человека (пол, профессия, территория и т.д.).

\section{ЛИТЕРАТУРА}

1. Шихова Т.М. Семантическая классификация фразеологизмов с эврисемичным по содержанию значением // Вестник Пермского университета. Серия Россия и зарубежная филология. Вып. 4, 2011. С. 80-87.

2. Абишева К.М. Кпроблеме выделения фразеологического концепта // Вопросы когнитивной лингвистики. №2. 2012. С. 34-43.

3. Алефиренко Н.Ф. Фразеологическое значение: природа, сущность, структура // Грани слова: сборн. научн. статей. М.: ЭЛПИС, 2005. С.21-26.

4. Aitchison J. Words in the mind: An introduction to the mental lexicon. Oxford: Basil Blackwell, 1987. $229 \mathrm{p}$.

5. Gibbs R.W. On the process of understanding idioms // Journal of psycholinguistic research. 1985. Vol. 14. PP. 465-472.

6. Levelt W. Lexical access in speech production. Cambridge: Blackwell. 1993.323 p.

7. Жернакова И.В. Идентификационные стратегии при опознании иноязычных идиом // Актуальные проблемы психолингвистики: слово и текст. Тверь, 1996. C.52-57.

8. Шумилина 0.С. Вариативность понимания фразеологизмов // Семантика слова и текста: психолингвистические исследования. Тверь, 1998. С.101-107.

9. Gibbs R.W., \& $0^{\prime}$ Brien J. E. Idioms and mental maintaining belifs is deimagery: The metaphorical motivation for idiomatic fending territory meaning. Cognition, 36 , 1990. PP. 35-68.

10. Schweigert W.A., Moates D.R. Familiar Idiom Comprehension // Journal of Psycholinguistic Research. 1988, Vol, 17. No. 4. PP. 281-296.

11. Dunbar G.L. The Cognitive Lexicon. Tübingen: Gunter Narr. 1991. PP. 154-161.

12. Swinney D. \& Cutler A. The access and processing of idiomatic expressions. JVLVB 18, 1979. PP. 523-534.

(с) Ергазина Алия Абдирамановна (yergazina1@mail.ru).

Журнал «Современная наука: актуальные проблемы теории и практики» 